\title{
PENGEMBANGAN MOBILE LEARNING BERBASIS ANDROID PADA MATA PELAJARAN BIOLOGI KELAS X SMA
}

\author{
Oleh : Ririn Amaliah Putri Sarah, Z. Mawardi Effendi \\ (Teknologi Pendidikan, Pascasarjana Universitas Negeri Padang) \\ e-mail: ririnamaliah25@yahoo.com
}

\begin{abstract}
Abstrak
Penelitian ini bertujuan untuk mengembangkan mobile learning berbasis android, mengetahui kualitas produk, serta mengetahui respon guru dan peserta didik terhadap aplikasi mobile learning berbasis android. Penelitian ini termasuk $k e$ dalam penelitian pengembangan $(R \& D)$, dengan model pengembangan $4 D$, yang meliputi empat tahapan, yaitu: pendefinisian (define), perancangan (design), pengembangan (develop), dan penyebaran (disseminate). Data diperoleh melalui validasi produk oleh ahli media, ahli materi, dan ahli bahasa, kemudian diuji cobakan kepada guru mata pelajaran biologi serta diujicoba kepada 30 peserta didik kelas X SMA. Berdasarkan penelitian ini diperoleh penilaian ahli materi sebesar 93,75\%, ahli media sebesar 93,75\%, ahli bahasa sebesar 84,38\%, tanggapan peserta didik sebesar 88,27\%; dan tanggapan guru sebesar 81,82\%. Dapat disimpulkan bahwa aplikasi mobile learning berdampak positif terhadap pemahaman peserta didik pada materi klasifikasi makhluk hidup, dengan nilai $N$ - Gain sebesar 0,72 dengan kategori tinggi. Sehingga aplikasi mobile learning dapat dijadikan sebagai media bantu yang layak bagi peserta didik dan guru.
\end{abstract}

Kata Kunci: Android, Media, Mobile learning, Biologi

\section{ANDROID-BASED MOBILE LEARNING DEVELOPMENT IN CLASS X BIOLOGY LEARNING FOR SENIOR HIGH SCHOOL}

\begin{abstract}
This study aims to develop android-based mobile learning, find out the quality of products, and determine the responses of teachers and students to android-based mobile learning applications. This research is included in development research $(R \& D)$, with the $4 D$ development model, which includes four stages, namely: defining, designing, developing, and disseminating. Data is obtained through product validation by media experts, material experts, and linguists, then tested on biology subject teachers and tested on 30 senior high school class $X$ students. Based on this study material expert judgment was $93.75 \%$, media expert was $93.75 \%$, linguist was $84.38 \%$, student responses were 88.27\%; and teacher responses by $81.82 \%$. It can be concluded that the mobile learning application has a positive impact on students' understanding of the material classification of living things, with an $N$-Gain value of 0.72 with a high category. So that mobile learning applications can be used as a suitable media for students and teachers.
\end{abstract}


Pengembangan Mobile Learning... (Ririn Amaliah Putri Sarah, Z. Mawardi Effendi)

Keyword: Android, Media, Mobile learning, Biology

\section{A. PENDAHULUAN}

Pendidikan merupakan bagian terpenting dalam kehidupan manusia dan merupakan aspek utama terciptanya sumber daya manusia yang berkualitas. Pendidikan dapat memanusiakan manusia menjadi individu yang bermanfaat bagi kehidupan, baik dalam kehidupan individu itu sendiri, bangsa maupun negara.

Dalam Undang-Undang Nomor 20 Tahun 2003 tentang Sistem Pendidikan Nasional menyebutkan bahwa "Pendidikan adalah usaha sadar terencana agar peserta didik secara aktif mengembangkan potensi dirinya untuk memiliki kekuatan spiritual keagamaan, mengendalikan diri, kepribadian, kecerdasan, ahlak mulia, serta keterampilan yang diperlukan dirinya, masyarakat, bangsa dan negara. Dengan tujuan untuk mengembangkan potensi peserta didik agar menjadi manusia yang beriman dan bertaqwa kepada Tuhan Yang Maha Esa, berakhlak mulia, sehat, berilmu, cakap, kreatif, mandiri dan menjadi warga negara yang demokratis serta bertanggung jawab".

Oleh karena itu, pendidikan harus dilaksanakan dengan sebaik-baiknya, sehingga sesuai dengan tujuan. Keberhasilan suatu bangsa terletak pada mutu pendidikan yang dapat meningkatkan kualitas sumber daya manusianya. Tujuan pendidikan sebenarnya sudah tertuang dalam pembukaan Undang Undang Dasar 1945 yang berbunyi "Mencerdaskan Kehidupan Bangsa dan Ikut Melasanakan Ketertiban Dunia”. Mata pelajaran Biologi di jenjang pendidikan SMA/MA termasuk ke dalam kelompok ilmu pengetahuan dan teknologi yang bertujuan untuk memperoleh kompetensi lebih lanjut serta membudayakan berpikir ilmiah secara kritis, kreatif dan mandiri (Depdiknas, 2006).

Mata pelajaran Biologi bertujuan agar peserta didik memiliki kemampuan untuk; (1) membentuk sikap positif terhadap mata pelajaran Biologi dengan menyadari keteraturan dan keindahan alam serta mengagungkan kebesaran Tuhan Yang Maha Esa, (2) memupuk sikap ilmiah yaitu jujur, objektif, terbuka, ulet, kritis, dan dapat bekerjasama dengan orang lain. (3) mengembangkan pengalaman untuk dapat mengajukan dan menguji hipotesis melalui percobaan, serta 
mengkomunikasikan hasil percobaan secara lisan dan tertulis. (4) mengembangkan kemampuan berpikir analisis, induktif, dan deduktif dengan menggunakan konsep dan prinsip Biologi. (5) mengembangkan penguasaan konsep, dan prinsip Biologi, dan saling keterkaitananya dengan IPA lainnya serta mengembangkan pengetahuan, keterampilan, dan sikap percaya diri. (6) menerapkan konsep dan prinsip Biologi untuk menghasilkan karya teknologi sederhana yang berkaitan kebutuhan manusia. (7) meningkatkan kesadaran dan berperan serta dalam menjaga kelestarian lingkungan (Surahman dan Surjono, 2017).

Keterbatasan waktu dan ruang yang sering kali menjadi permasalahan, kini dapat teratasi dengan hadirnya pembelajaran berbasis elektronik atau yang dikenal dengan electronic learning (e-learning). E-learning adalah sebuah pendekatan untuk memfasilitasi dan meningkatkan pembelajaran melalui teknologi komputer dan komunikasi. Penggunaan peralatan elektronik yang tidak fleksibel ini tentunya menjadi salah satu kendala dalam penerapan e-learning. Namun, seiring berjalannya waktu, teknologi terus memberikan solusi bagi dunia pendidikan, salah satunya sistem pembelajaran berbasis mobile atau yang dikenal dengan istilah mobile learning (m-learning).

Salah satu pertimbangan dalam mengembangkan smartphone menjadi media pembelajaran m-learning adalah basis yang dilakukan sistem operasi yang digunakan. Sistem operasi merupakan penghubung antara aplikasi dengan hardware sehingga pengguna dapat menjalankan fungsi-fungsi tertentu. Sistem operasi yang banyak digunakan pada telepone pintar (smartphone) dan tablet PC adalah android. Anggraeni dan Kustijono (2013) Android merupakan sistem operasi yang paling diminati di masyarakat karena memiliki kelebihan seperti sifat open source yang memberikan kebebasan para pengembang untuk menciptakan aplikasi. Android merupakan sistem operasi perangkat mobile yang lebih unggul dibanding Simbian dan Windows Mobile.

Berdasarkan hasil observasi yang telah dilakukan di SMA Negeri 8 Padang pembelajaran masih berpusat pada guru (teacher center). Bahan ajar pembelajaran yang sering digunakan di SMA Negeri 8 Padang adalah power 
point, video pembelajaran, buku teks pelajaran, dan LKS (modul). Dalam pelajaran Biologi buku yang ada terlalu tebal sehingga menyebabkan siswa malas untuk membaca. Bahan ajar tersebut tidak bisa sewaktu-waktu digunakan oleh siswa dan dirasa kurang praktis dan membuat siswa merasa jenuh.

Biologi merupakan ilmu yang sudah cukup tua, karena sebagian besar berasal dari keingintahuan manusia tentang dirinya, tentang lingkungannya, dan tentang kelangsungan jenisnya. Biologi bukan hanya sekedar penguasaan kumpulan pengetahuan yang berupa fakta-fakta, konsep-konsep, atau prinsip-prinsip saja tetapi juga merupakan suatu proses penemuan.

Proses pembelajarannya menitikberatkan pada pemberian pengalaman langsung kepada siswa untuk mengembangkan kemampuan agar menjelajahi dan memahami alam sekitar secara ilmiah. Pengalaman langsung dapat dilakukan melalui kegiatan praktikum di laboratorium atau kegiatan observasi ke alam sekitar. Kegiatan observasi kadang memiliki berbagai kendala yaitu kurangnya fasilitas, biaya, dan objek sulit untuk ditemui. materi dan peserta didik lebih mudah memahami materi yang diajarkan.

Menurut Syah (2014) penggunaan media yang tepat dapat meningkatkan minat belajar peserta didik. Pemilihan media yang tepat dan menarik dapat memusatkan perhatian yang intensif serta mampu membangkitkan minat peserta didik untuk menguasai pengetahuan yang disampaikan melalui penggunaan media tersebut sehingga hal ini dapat mempengaruhi kualitas pencapaian hasil belajar peserta didik. Selanjutnya Sadiman (2007) peserta didik akan merasa termotivasi untuk menyimak informasi yang disampaikan melalui media tersebut.

Dari uraian di atas menunjukkan bahwa pengembangan media mobile learning berbasis android menjadi salah satu alternatif pembelajaran yang mampu mendukung kegiatan belajar mengajar agar lebih efektif, efisien dan real time.

\section{B. METODOLOGI PENELITIAN}

Penelitian yang digunakan adalah penelitian dan pengembangan (Research \& Development) atau R\&D. Metode penelitian dan pengembangan adalah metode 
penelitian yang digunakan untuk menghasilkan produk tertentu, dan menguji keefektifan dari produk tersebut.

Model pengembangan dalam penelitian ini mengikuti alur dari Sivasailam. Model pengembangan 4-D tahap utama yaitu Define, Design, Develop, dan Disseminate atau diadaptasikan menjadi model 4-P, yaitu pendefinisian, perancangan, pengembangan, dan penyebaran. Penerapan langkah utama dalam penelitian tidak hanya merunut versi asli tetapi disesuaikan dengan karakteristik subjek dan tempat asal examinee.

Tahap pengembangan mobile learning berbasis android terdiri dari validasi ahli dan uji pengembangan. Validasi ahli terdiri dari 3 ahli yaitu, ahli materi, ahli media, dan ahli bahasa. Kemudian untuk mendapatkan hasil yang efektif melalui uji Paired Sample T-test dan gain test Analisis Paired Sample Ttest dilakukan dengan aplikasi SPSS untuk melakukan uji T terhadap data pretest dan post-test. Teknik analisis data gain-test dilakukan dengan menghitung nilai gain $(\mathrm{g})$ untuk mengetahui peningkatan pemahaman siswa.

\section{HASIL PENELITIAN DAN PEMBAHASAN}

Pada penelitian ini telah di kembangkan produk penelitian berupa Mobile Learning Berbasis Android Pada Mata Pelajaran Biologi Kelas X SMA. Dalam penelitian ini menggunakan model pengembangan 4-D setiap tahapnya di ikuti dan menghasilkan produk Mobile Learning Berbasis Android yang valid, praktis, dan efektif.

\section{Uji Validasi}

Desain awal media mobile learning berbasis android sebelum diujikan pada subjek penelitian harus divalidasi terlebih dahulu oleh ahli. Tujuannya adalah untuk mengetahui kelayakan desain awal media mobile learning berbasis android tersebut. Validasi ini dilakukan oleh dosen ahli yang terdiri dari dosen ahli materi dari Jurusan Pendidikan Biologi UNP, dosen ahli media dari Jurusan Pendidikan Teknik Elektro UNP, dosen ahli bahasa dari Jurusan Pendidikan Bahasa FBS UNP dan praktisi dilakukan oleh guru Biologi SMA Negeri 8 Padang. 
Dari Uraian hasil validasi para ahli dan uji pengembangan mobile lerning berbasis android dapat kita simpulkan pada tabel 1.

Tabel 1. Rekapitulasi Penilaian Validitas

\begin{tabular}{|c|l|c|c|}
\hline No & Uraian & Skor & Kategori \\
\hline 1 & Materi & 93,75 & Sangat Valid \\
\hline 2 & Media & 93,75 & Sangat Valid \\
\hline 3 & Bahasa & 84,38 & Valid \\
\hline
\end{tabular}

Merujuk pada kategori kevalidtan, maka hasil validitas pembembangan mobile learning berbasis Android termasuk dalam kategori sangat valid. Hasil analisis validitas materi, media dan bahasa pembelajaran mobile learning berbasis Android pada mata pelajaran Biologi dapat dilihat pada gambar 1 .

\section{Hasil Uji Validitas}

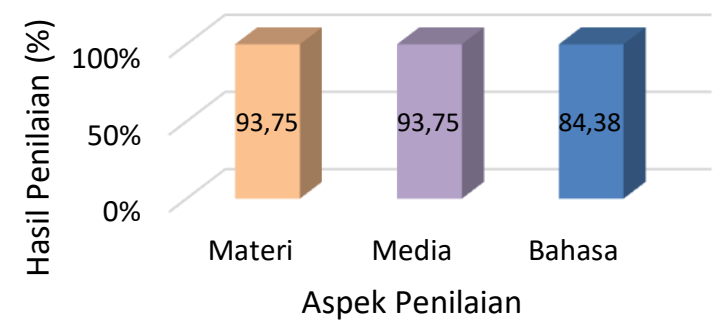

\section{Gambar 1. Grafik Hasil Uji Validitas Mobile Learning Berbasis Android}

Setelah media pembelajaran mobile learning berbasis android dinyatakan valid, dan mendapat beberapa saran perbaikan oleh validator. Sebelum penerapan produk secara menyeluruh dilakukan perbaikan terhadap produk yang dikembangkan agar mendapatkan data praktikalitas yang baik sesuai dengan tujuan penelitian.

\section{Uji Pratikalitas}

Penilaian praktikalitas dilakukan terhadap 30 orang siswa kelas X.1 dan 1 orang guru Biologi SMA Negeri 8 Padang. Dari Uraian hasil pratikalitas siswa dan guru terhadap mobile lerning berbasis android dapat kita simpulkan pada tabel 2. 
Tabel 2. Rekapitulasi Penilaian Pratikalitas

\begin{tabular}{|c|l|r|c|}
\hline No & Uraian & Skor & Kategori \\
\hline 1 & Siswa & 88,27 & Sangat Valid \\
\hline 2 & Guru & 81,82 & Valid \\
\hline
\end{tabular}

Berdasarkan hasil uji praktikalitas sisa dan guru, maka didapat rata-rata praktikalitas media mobile learning berbasis android pada siswa sebesar 88,27\% dengan kategori sangat praktis. Dan rata-rata praktikalitas media mobile learning berbasis android pada guru sebesar $81,82 \%$ dengan kategori praktis.

Merujuk pada kategori kepraktisan, maka hasil praktikalitas siswa dan guru termasuk dalam kategori sangat praktis. Hasil analisis praktikalitas implementasi terbatas, dan implementasi penuh dapat dilihat pada gambar 2.

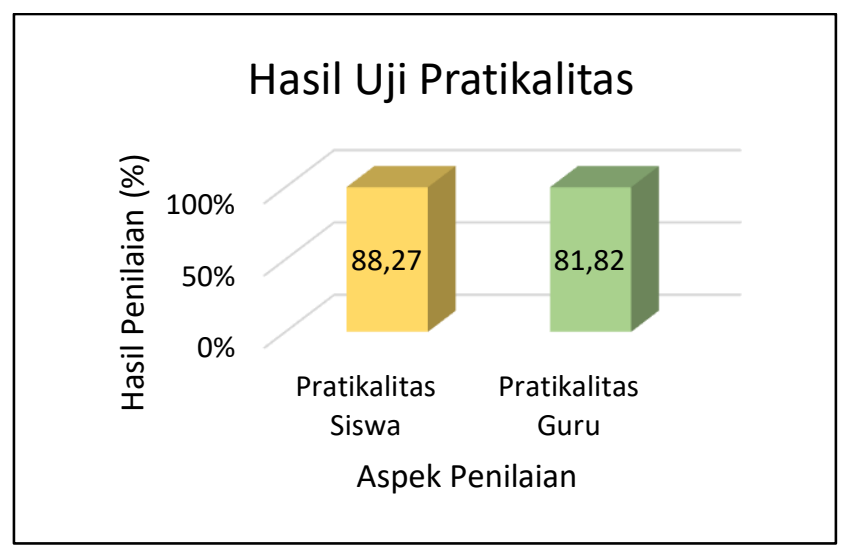

\section{Gambar 2. Grafik Hasil Uji Pratikalitas Mobile Learning Berbasis Android}

Maka dapat disimpulkan bahwa penggunaan mobile learning berbasis Android sangat praktis untuk di gunakan dalam mata pelajaran Biologi dan memberikan pengaruh positif dalam pelajaran dan dapat meningkatkan minat siswa dalam belajar.

\section{Uji Efektivitas}

Uji efektivitas dilakukan dengan memberikan pretest dan posttest kepada 30 orang siswa. Data uji efektivitas diuji dengan program SPSS Statistic 16 (Statistic Product for Service Solution) dengan menggunakan Paired Sample Ttest dan penghitungan nilai gain. 
Uji Paired Sample T-test

(1) Analisis dan interpretasi output Paired Samples Statistic

Tabel 3. Paired Samples Statistic

\begin{tabular}{|c|c|c|c|c|}
\hline & Mean & $\mathrm{N}$ & Std. v & $\begin{array}{l}\text { Std. Error } \\
\text { Mean }\end{array}$ \\
\hline Pair 1 Pre Test & 52.80 & 30 & 12.288 & 2.243 \\
\hline Post Test & 86.67 & 30 & 6.989 & 1.276 \\
\hline
\end{tabular}

Tabel 3 merupakan ringkasan perbandingan statistik pada pretest dan posttest yang menunjukkan bahwa rata rata skor pretest siswa adalah sebesar 52,80 dengan standar deviasi 12,29 sedangkan rata-rata skor posttest siswa adalah sebesar 86,67 dengan standar deviasi sebesar 6,989. Berdasarkan analisis pada paired samples statistic tersebut maka dapat dilihat bahwa terdapat kenaikan rata-rata skor pretest dan posttest siswa sebesar 33,87 .

(2) Analisis dan interpretasi output Paired Samples Test

Tabel 4. Paired Samples Test

\begin{tabular}{|cc|c|c|c|c|c|}
\hline \multirow{2}{*}{} & \multicolumn{2}{|c|}{$\begin{array}{c}\text { Paired } \\
\text { Differences }\end{array}$} & \multirow{2}{*}{$\mathrm{t}$} & $\mathrm{df}$ & $\begin{array}{c}\text { Sig. (2- } \\
\text { tailed) }\end{array}$ \\
\cline { 2 - 4 } & Mean & Std.v & & & \\
\hline Pair 1 & $\begin{array}{l}\text { Pre Test - } \\
\text { Post Test }\end{array}$ & -33.867 & 11.590 & -16.005 & 29 & .000 \\
\hline
\end{tabular}

Berdasarkan tabel 4, dapat diuji perbedaan rata- rata skor pretest dan posttest siswa adalah 33,87. Nilai t yang diperoleh adalah sebesar 16,005 dengan signifikansi 0,000. Karena nilai signifikansi $0,000<0,05$ maka dapat disimpulkan bahwa terdapat perbedaan antara nilai pretest dan posttest pada siswa.

\section{Perhitungan Gain Score}

Untuk mengetahui peningkatan pemahaman siswa, maka diukur dengan menggunakan nilai gain. Diketahui bahwa rata-rata skor posttest siswa adalah sebesar 86,67 rata-rata skor pretest siswa adalah sebesar 
52,80, dan skor maksimum siswa adalah 100,00. Dari data tersebut, maka perhitungan nilai gain-nya adalah sebagai berikut.

$$
\begin{aligned}
& g=\frac{\text { skor posttest - skor pretest }}{\text { skor maksimum - skor pretest }} \\
& g=\frac{86,67-52,80}{100,00-52,80} \\
& g=0,72
\end{aligned}
$$

Berdasarkan perhitungan di atas, maka dapat diketahui bahwa nilai gain adalah sebesar 0,72 sehingga kriteria nilai gain menurut Hake adalah Tinggi. Hal ini menunjukkan kemampuan media mobile learning berbasis android dalam meningkatkan pemahaman siswa mengenai materi Klasifikasi Makhluk Hidup tergolong Tinggi.

\section{SIMPULAN}

Berdasarkan penelitian dan pengembangan mobile learning berbasis Android pada mata pelajaran Biologi kelas X SMA disimpulkan hasil validasi materi sebesar 93,75\% menunjukkan kriteria sangat valid, validasi media sebesar 93,75\% menunjukkan kriteria sangat valid, dan validasi bahasa sebesar 84,38\% menunjukkan kriteria valid, validasi oleh ahli dilakukan perbaikan sebanyak satu kali.

Hasil uji praktikalitas penggunaan mobile learning berbasis android untuk praktikalitas siswa sebesar $88,27 \%$ menunjukkan kriteria sangat praktis serta praktikalitas guru sebesar $81,82 \%$ menunjukkan kriteria praktis setelah dilakukan penilaian kepraktisan. Hasil efektivitas produk mobile learning berbasis android pada mata pelajaran Biologi kelas X SMA menunjukkan kriteria efektif. Hasil belajar siswa berdasarkan pretest dan posttest diuji menggunakan rumus T Paired didapat nilai Nilai t yang diperoleh adalah sebesar 16,005 dengan signifikansi 0,000. Karena nilai signifikansi $0,000<0,05$ maka dapat disimpulkan bahwa terdapat perbedaan antara nilai pretest dan posttest pada siswa. 
Pengembangan Mobile Learning... (Ririn Amaliah Putri Sarah, Z. Mawardi Effendi)

\section{DAFTAR PUSTAKA}

Anggraeni, R. D., \& Kustijono, R. (2013). Pengembangan Media Animasi Fisika Pada Materi Cahaya dengan Aplikasi Flash Berbasis Android. Jurnal Penelitian Fisika dan Aplikasinya (JPFA), 3(1), 11 -18.

Depdiknas (2006). Permendiknas Nomor 22 Tahun 2006 Tentang Standar Isi Sekolah Menengah Atas. Jakarta: Depdiknas.

Syah, Muhibbin. (2014). Psikologi Pendidikan. Bandung: PT. Remaja Rosdakarya.

Sadiman, Arief S. dkk. (2007). Media Pendidikan: Pengertian, Pengembangan, dan Pemanfaatannya. Jakarta: PT. Raja Grafindo Persada.

Surahman, E., \& Surjono, H. D. (2017). Pengembangan Adaptive Mobile Learning pada Mata Pelajaran Biologi SMA sebagai Upaya Mendukung Proses Blended Learning. Jurnal Inovasi Teknologi Pendidikan, 4(1), 2637. 